\title{
MORPHOLOGICAL STUDIES ON IMPLANTATION IN MARSUPIALS
}

\author{
R. L. HUGHES \\ School of Zoology, University of New South Wales, \\ P.O. Box 1, Kensington, New South Wales 2033, Australia
}

This paper reviews some of the more important literature relating to the morphological aspects of marsupial implantation in conjunction with hitherto unpublished observations. The data, although fragmentary, are derived from a wide variety of marsupial species and are presented in support of the thesis that fetal-maternal relationships in marsupials can most appropriately be divided into two phases. The first phase occupies up to two-thirds or more of pregnancy while the blastocyst undergoes expansion. The three primary germ layers (endoderm, mesoderm and ectoderm) are established and embryonic development proceeds at least as far as the pre-fetal or early fetal stage. Implantation is not known to occur in any marsupial during this period as an intact shell membrane completely separates fetal and maternal tissues. The second phase begins during the terminal third of gestation and is initiated by the rupture of the shell membrane. This is the period when almost all fetal differentiation occurs, and in only some marsupials does the trophoblast exhibit invasive properties that result in either a rudimentary implantation or, in one group (the Peramelidae), a relatively typical implantation reminiscent of that found in eutherian mammals.

The details of the morphological events during the first and second phases of marsupial development will now be considered separately. Although the photomicrographs and much of the accompanying text are concerned with only three marsupials, Trichosurus vulpecula (brush possum), Phascolarctos cinereus (koala) and Perameles nasuta (bandicoot), they are considered to provide an adequate coverage of the range of fetal-maternal adaptation relating to implantation in marsupials as a whole.

THE FIRST PHASE OF MARSUPIAL DEVELOPMENT

At the beginning of the first phase the vitellus of the egg is invested by three acellular egg membranes. The innermost of these is the zona pellucida of ovarian origin. The zona pellucida in turn becomes coated by two further egg membranes (the tertiary egg membranes, the mucoid coat and the shell membrane) during the passage of the egg through the Fallopian tube to the uterus (Pl. 1, Fig. 1). The formation and fate of each of these three egg membranes will now be considered separately.

\section{The zona pellucida}

The marsupial zona pellucida, as in eutherian mammals, is of ovarian origin and is fully formed at ovulation. In Trichosurus vulpecula and various other mar- 
supial species, it has the histochemical properties of a weakly acidic proteincarbohydrate complex (Hughes, 1974). Trichosurus vulpecula has a thin zona pellucida, usually less than $6 \mu \mathrm{m}$ thick (range 0.5 to $7.9 \mu \mathrm{m}$ ) and this is presumably a typical marsupial feature. Sharman (1961) has reported a zona of about $1 \mu \mathrm{m}$ in thickness for a four-celled uterine egg in Trichosurus vulpecula, and in unilaminar blastocysts of Macropus eugenii in diapause the zona had a thickness of from 0.5 to $1.6 \mu \mathrm{m}$ (Hughes, 1974). According to Hill (1910) the zona of both ovarian eggs and unsegmented uterine eggs was about $2 \mu \mathrm{m}$ in thickness in Dasyurus viverrinus. Hartman (1916) has also reported a thin zona pellucida in Didelphis virginiana ranging in thickness from $0 \cdot 8$ to $4 \mu \mathrm{m}$ in tubal eggs.

The marsupial zona pellucida has a transitory existence and as in Dasyurus viverrinus (Hill, 1910) it probably disappears with the expansion of the unilaminar blastocyst. In Trichosurus vulpecula the zona is present in both unfertilized uterine eggs and unilaminar blastocysts until at least 4 days after oestrus but is not found in bilaminar blastocysts (Hughes, 1974). Hill's (1910) observations on Dasyurus viverrinus and several other marsupial species led him to conclude that the zona pellucida played a vital rôle in the direct mode of formation of the marsupial unilaminar blastocyst. Renfree (1972) has reported the presence of a zona pellucida in unilaminar blastocysts of Macropus eugenii and Sharman (1961) described a zona pellucida in the fertilized tubal egg of Setonix brachyurus but stated that although it was probably present in the unilaminar blastocyst stage, it could not be recognized with certainty.

\section{The mucoid coat}

All marsupial eggs so far investigated acquire a laminated mucoid coat (the 'albumen layer' of the earlier literature) during their passage through the Fallopian tube (MC, Pl. 1, Fig. 1). In Trichosurus vulpecula and other marsupials, the mucoid coat has the histochemical properties of a strongly sulphated glycoprotein and is secreted by nonciliated cells concentrated in the ampulla and isthmus regions of the simple luminal epithelium of the Fallopian tube (Hughes, 1974).

The mucoid coat when fully formed varies greatly in thickness both between and within species. In Dasyurus viverrinus it is relatively thin, ranging between 15 and $22 \mu \mathrm{m}$, while in Didelphis aurita and Didelphis virginiana it attains a thickness of up to 140 and $150 \mu \mathrm{m}$ respectively (Hill, 1918; Hartman, 1916). In Trichosurus vulpecula the fully formed mucoid coat has a maximum thickness which ranges from about $45 \mu \mathrm{m}$ to $90 \mu \mathrm{m}$ (Hughes, 1974).

The mucoid coat disappears at different stages of embryonic development according to the species. Hill (1910) found that in Dasyurus viverrinus it had all but disappeared by about the 16-cell stage and it was said to be absent in the just completed unilaminar blastocyst $0.4 \mathrm{~mm}$ in diameter. This resulted in the cellular trophoblast, zona pellucida and shell membrane being brought into intimate apposition. Hill considered that the embryonic development of Dasyurus viverrinus was characterized by a particularly early expansion of the unilaminar blastocyst, but it should be noted that the mucoid coat had disappeared before the onset of this expansion. In Bettongia cuniculus the mucoid 
coat markedly thins in the advanced unilaminar blastocyst stage and is not found in bilaminar blastocysts (Kerr, 1935). Sharman (1961) observed a mucoid coat in Setonix brachyurus up to the unilaminar blastocyst stage but this was not found in later stages of embryonic development. Hill (1918) reported the absence of the mucoid coat at the bilaminar blastocyst stage in Didelphis aurita. In Trichosurus vulpecula the mucoid coat thins with the expansion of the unilaminar blastocyst on about the 4th to 6th day after oestrus and it disappears during the bilaminar blastocyst stage (Pl. 1, Fig. 2) on approximately the 7 th to 9 th days after oestrus (Hughes, 1974). In Didelphis virginiana the mucoid coat thins with the expansion of the bilaminar blastocyst and has all but disappeared $6 \frac{1}{2}$ to $7 \frac{1}{2}$ days after mating at about, or just before, the proliferation of mesoderm (Hartman, 1916, 1919, 1928; McCrady, 1938). The longest reported persistence of the mucoid coat occurs in Schoinobates volans, in which it had nearly all been absorbed by the somite stage (Bancroft, 1973).

\section{The shell membrane}

A thin shell membrane has been reported to invest the mucoid coat of some eggs recovered from the Fallopian tubes of several marsupial species: Dasyurus viverrinus (Hill, 1910), Didelphis virginiana (Hartman, 1916, 1919), Setonix brachyurus (Sharman, 1961). In three tubal eggs of Trichosurus vulpecula the shell membrane had a thickness ranging between 3.2 and $6.3 \mu \mathrm{m}$ (SH, Pl. 1, Fig. 1) (Hughes, 1974).

The deposition of the shell membrane continues after eggs enter the uterus. In all marsupial species so far examined the uterine eggs are always invested by a shell membrane (Hill, 1910; Hughes, 1974), which attains its maximum thickness before the unilaminar blastocyst undergoes expansion. Early uterine eggs with a shell membrane thickness ranging between $1 \mu \mathrm{m}$ and 1.6 $\mu \mathrm{m}$ have been reported for Phascolarctos cinereus (Caldwell, 1887), Dasyurus viverrinus (Hill, 1910), Didelphis virginiana (Hartman, 1916) and Didelphis aurita (Hill, 1918). However, the maximum shell membrane thickness found in Didelphis aurita was $3 \mu \mathrm{m}$ and in Dasyurus viverrinus and Phascolarctos cinereus it was 8 and $10 \mu \mathrm{m}$, respectively. In Trichosurus vulpecula Hughes (1974) found that in seven cleaving uterine eggs the mean shell membrane thickness was $4.5 \mu \mathrm{m}$ and in seven unilaminar blastocysts this had increased to a mean of $7.4 \mu \mathrm{m}$; a maximum thickness of 6 to $10 \mu \mathrm{m}$ was attained in unfertilized eggs and unilaminar blastocysts at about the 2 nd to 4 th day after oestrus.

Observations by Hughes (1974) on the shell membrane of Trichosurus vulpecula and six other marsupial species, Trichosurus caninus, Macropus eugenii, Macropus robustus, Megaleia rufa, Phascolarctos cinereus and Isoodon macrourus, have shown that the shell membrane is a resistant proteinaceous material, rich in disulphide bonds and with the histochemical properties of an ovokeratin.

Boyd (1924) and Hartman (1939) believed that the shell membrane of Didelphis virginiana was formed by tubular shell glands that penetrated the luminal epithelium of the lower portion of the Fallopian tube. However, a thorough investigation of this region in Trichosurus vulpecula by Hughes (1974) showed that no tubular shell glands are present and that although eggs from the Fallopian tube of Trichosurus vulpecula may possess a shell membrane its 
precursor is a uterine secretion particularly abundant in the lumen of the tubular endometrial glands.

In Trichosurus vulpecula the shell membrane diminishes in thickness with the expansion that accompanies the formation of the bilaminar blastocyst ( $\mathrm{Pl}$. 1, Fig. 2) about 7 to 9 days after oestrus. The shell membrane had thinned from its maximum thickness at 6 to $10 \mu \mathrm{m}$ in the unilaminar blastocyst stage to a mean thickness of $2.4 \mu \mathrm{m}$ in three bilaminar blastocysts. Still further thinning of the intact shell membrane was evident in two trilaminar blastocysts (one of these stages exhibited a primitive streak and was at about 10 days after oestrus) where it had a mean thickness of $2.0 \mu \mathrm{m}$. In two young fetal stages the shell membrane had ruptured in several places and was $0.5 \mu \mathrm{m}$ thick (Pl. 1, Fig. 3). Thus in Trichosurus vulpecula an unruptured shell membrane was believed to separate fetal and maternal tissues until at least two-thirds of the 18 days of gestation had elapsed (Hughes, 1974). This confirms the observation of Sharman (1961) who found that in Trichosurus vulpecula the shell membrane was present until at least some mesoderm had extended beyond the embryonal area in an embryo at 12.5 days of gestation. Both Sharman (1961) and Hughes (1974) have described ruptured remnants of the shell membrane persisting in association with fetal membranes of full-term Trichosurus vulpecula fetuses.

In Dasyurus viverrinus, Hill (1910) reported the thinning of the intact shell membrane accompanying the expansion of the unilaminar blastocyst, but in Didelphis virginiana the shell membrane has been stated to retain its variable maximum thickness until after the formation of the bilaminar blastocyst (Hartman, 1916). Similarly, Kerr (1935) noted that in Bettongia cuniculus the shell membrane exhibited great individual variation in thickness but began to thin rapidly with the formation of the bilaminar blastocyst. Flynn (1930) found that a very thin shell membrane separated a medullary plate blastocyst stage of Bettongia cuniculus from the uterine epithelium.

The time of rupture of the shell membrane in relation to the stage of gestation and extent of embryonic development is known for only six marsupial species:

\section{EXPLANATION OF PLATE 1}

Fig. 1. An unfixed, cleaving egg recovered from the isthmus region of the Fallopian tube of Trichosurus vulpecula. The overall diameter of the vitellus (VIT) was about $229 \mu \mathrm{m}$. This consisted of sixteen blastomeres of unequal size surrounding a primitive blastocoele. The cell mass was enclosed by a thin zona pellucida. This was in turn invested by a mucoid coat (MC) $79 \mu \mathrm{m}$ in thickness containing numerous sperm remnants. A shell membrane (SH) of relatively uniform thickness $(5.9 \mu \mathrm{m})$ invested the mucoid coat.

Frg. 2. A sectioned, bilaminar blastocyst recovered from the uterus of Trichosurus vulpecula. The overall diameter of the trophoblastic ectoderm was $3.2 \mathrm{~mm}$. Both the zona pellucida and mucoid coat were absent and the shell membrane (SH) of $1.3 \mu \mathrm{m}$ thickness was closely applied to the entire outer surface of the ectodermal layer.

Fig. 3. Portion of a transversely sectioned pregnant uterus of Trichosurus vulpecula. The young fetus had an overall length of $9 \mathrm{~mm}$ and the oval yolk-sac had major and minor axes of 19 and $11 \mathrm{~mm}$ respectively. The zona pellucida and mucoid coat were absent. The shell membrane (SH) was ruptured in places and was not closely applied to either the bilaminar yolk-sac (BI YS) or to the luminal epithelium of the uterine endometrium (UT EP).

Fic. 4. A fixed, advanced fetal stage of Potorous tridactylus. The fetus of $8.7 \mathrm{~mm}$ in overall length was completely enclosed by folds of the yolk-sac. The trophoblastic ectoderm of the yolk-sac was not fused at any point with the uterine epithelium. The major and minor axes of the yolk-sac were 18 and $12 \mathrm{~mm}$ respectively. A prominent equatorial sinus terminalis (ST) marked the boundary between the bilaminar (BI YS) and trilaminar (TRI YS) portions of the yolk-sac. 
PLATE ]

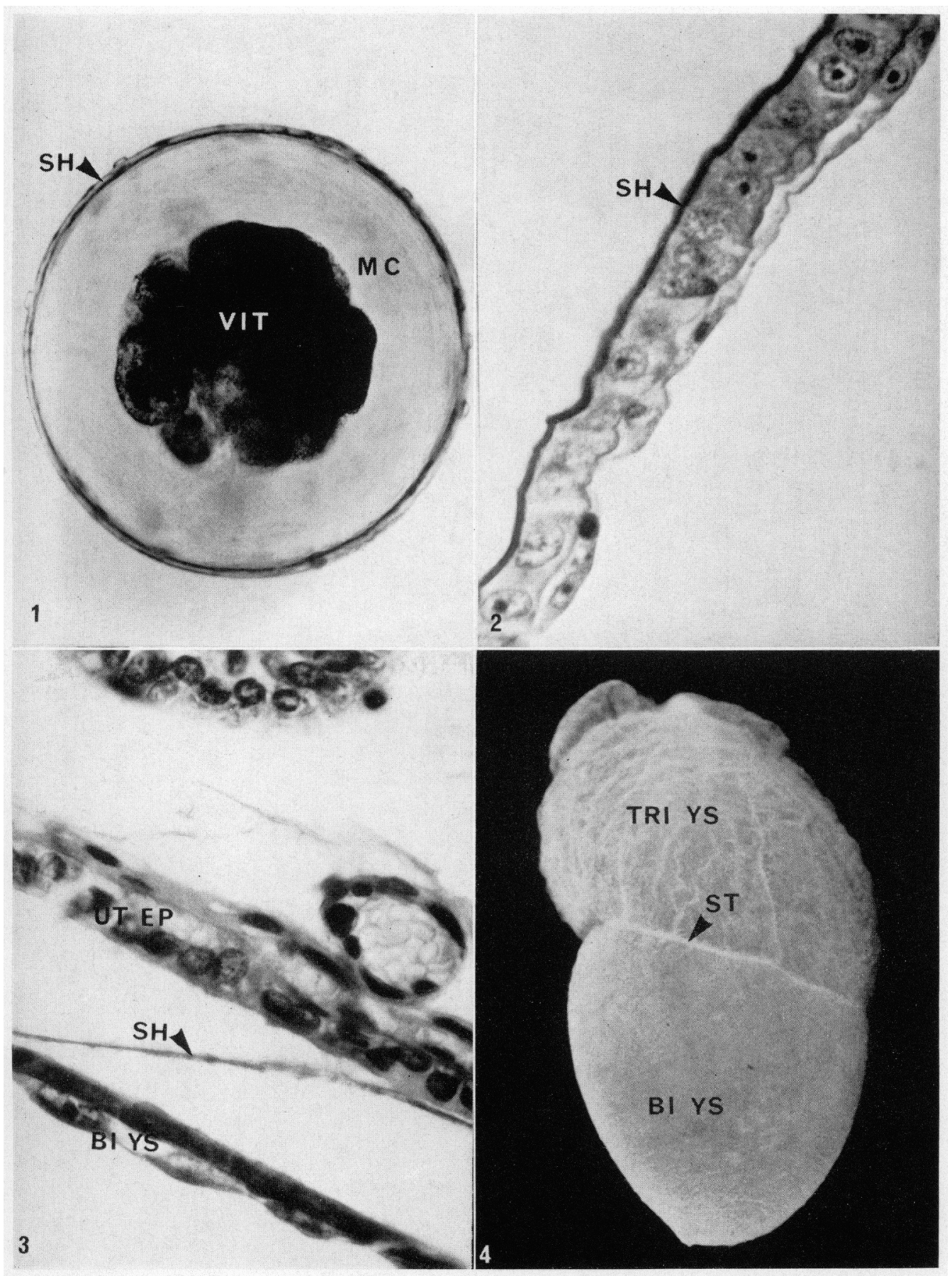

(Facing p. I 76) 
Didelphis virginiana, Macropus eugenii, Perameles nasuta, Setonix brachyurus, Sminthopsis crassicaudata and Trichosurus vulpecula (Table 1). It can be seen from Table 1 that in all six of these species the shell membrane remains intact until at least the beginning of the terminal third of pregnancy when either a pre-fetal or early fetal stage of embryonic differentiation has been reached. A female Sminthopsis crassicaudata killed 10 days after mating had embryos at the early primitive streak stage with an overall diameter of about $3.5 \mathrm{~mm}$ in both uteri. The zona pellucida and mucoid coat were absent and an intact shell membrane of about $1 \mu \mathrm{m}$ in thickness was loosely applied to the entire surface of the trophoblastic ectoderm. Ewer (1968) reported that parturition in Sminthopsis crassicaudata occurred approximately 16 days after the first of a series of copulations that extended over 1 to 3 days. Pre-fetal stages of embryonic development

Table 1. Most advanced stage of marsupial development attained with an intact shell membrane

\begin{tabular}{|c|c|c|c|c|}
\hline Species & $\begin{array}{l}\text { Gestation } \\
\text { period } \\
\text { (days) }\end{array}$ & $\begin{array}{l}\text { Shell membrane } \\
\text { unruptured } \\
\text { (days after } \\
\text { mating) }\end{array}$ & $\begin{array}{l}\text { Stage of } \\
\text { embryonic } \\
\text { development }\end{array}$ & Reference \\
\hline $\begin{array}{l}\text { Didelphis } \\
\quad \text { virginiana }\end{array}$ & 13 & 8 & Pre-fetal somite stage & McGrady (1938) \\
\hline $\begin{array}{r}\text { Macropus } \\
\text { eugenii }\end{array}$ & 27 & 19 & Early fetus & Renfree (1973) \\
\hline $\begin{array}{l}\text { Perameles } \\
\text { nasuta }\end{array}$ & 12 & 7 to 8 & $\begin{array}{l}\text { Primitive streak to pre- } \\
\text { fetal }\end{array}$ & $\begin{array}{l}\text { A. G. Lyne } \\
\text { (personal } \\
\text { communication) }\end{array}$ \\
\hline $\begin{array}{l}\text { Setonix } \\
\quad \text { brachyurus }\end{array}$ & 27 & 19 & $\begin{array}{l}\text { Early fetus with unfused } \\
\text { amniotic folds }\end{array}$ & Sharman (1961) \\
\hline $\begin{array}{l}\text { Sminthopsis } \\
\text { crassicaudata }\end{array}$ & 16 & $10^{*}$ & Early primitive streak* & Ewer (1968) \\
\hline $\begin{array}{l}\text { Trichosurus } \\
\text { vulpecula }\end{array}$ & $17 \frac{1}{2}$ & 14 & $\begin{array}{l}\text { Pre-fetal somite stage } \dagger \\
\text { to early fetus } \ddagger\end{array}$ & $\begin{array}{l}\text { Sharman (1963) } \\
\text { (in Tyndale- } \\
\text { Biscoe, 1963) }\end{array}$ \\
\hline
\end{tabular}

* Hughes (this investigation).

+ Sharman (1961) reported that in a Trichosurus vulpecula embryo $12 \frac{1}{2}$ days after mating the embryonic vesicle measured $7.5 \mathrm{~mm}$ in diameter and that the mesoderm had hardly extended beyond an embryonal disc of $3.5 \mathrm{~mm}$ long. He stated that the fetus formed 2 to 3 days later.

$\ddagger$ A colour slide provided by Dr C. H. Tyndale-Biscoe showed that an early fetus had differentiated in Trichosurus vulpecula at 12 days after mating.

with an intact or largely intact shell membrane, but at an unknown stage of gestation, have been reported for three other marsupial species: Phascolarctos cinereus (Caldwell, 1884, 1887); Perameles obesula (Hill, 1897) and Schoinobates volans (Bancroft, 1973). I have found that in both Macropus robustus and Megaleia rufa an unruptured intact shell membrane invests the embryo at the pre-fetal somite stage.

Presumably in most if not in all marsupials, embryonic development proceeds to the terminal stages of gestation, beyond the somite stage, and up to the formation of the fetal rudiments, before the shell membrane ruptures. Consequently, no opportunity for implantation occurs prior to this stage of development. These events are somewhat reminiscent of the intrauterine hatching exhibited by some ovoviviparous vertebrates, although the two situations are not strictly comparable. 
Prolonged persistence of the shell membrane and a relatively slow rate of embryonic development are also features of monotreme development. Broom (1895) reported that the interval between mating and egg laying in the echidna was about 28 days. Wilson \& Hill (1908) stated that an echidna embryo in their possession, removed from an egg newly laid in captivity, corresponded roughly with a chick embryo at about the end of the 3rd day of incubation. Caldwell (1884) compared the embryo of the newly laid platypus egg to that of a chick of about $36 \mathrm{hr}$ of incubation and Wilson \& Hill (1908) reported that two sub-terminal intrauterine platypus eggs contained embryos with seventeen or eighteen pairs of somites. These findings agree with my own observations on two fully developed intrauterine platypus eggs recovered from an animal captured near Yass, New South Wales, on 28th September 1973 and killed 1 week later. The eggs were oval and of approximately equal size. The major and minor axes of the parchment-like shell were 17 and $15 \mathrm{~mm}$ respectively. The 'pre-fetal' embryo had an overall length of $15 \mathrm{~mm}$ and possessed about twenty pairs of somites. The anterior portion of the neural tube exhibited well differentiated optic vesicles and rudiments of head fold had developed. Although no embryonic blood vessels were seen, blood islands had commenced to form. Thus the stage of embryonic development attained when the monotreme egg is laid is comparable to that of marsupials at about the time when the shell membrane ruptures.

THE SECOND PHASE OF MARSUPIAL DEVELOPMENT

The second phase of marsupial development commences with the rupture of the shell membrane and is characterized by the differentiation of the fetus and a variable degree of trophoblastic invasiveness according to the species

Table 2. Incidence of implantation in marsupial species

\begin{tabular}{|c|c|c|}
\hline $\begin{array}{c}\text { Trophoblast } \\
\text { not invasive } \\
\text { (no implantation) }\end{array}$ & $\begin{array}{c}\text { Trophoblast of yolk-sac } \\
\text { slightly invasive } \\
\text { (rudimentary implantation) }\end{array}$ & $\begin{array}{l}\text { Highly invasive } \\
\text { chorionic villi } \\
\text { (typical implantation) }\end{array}$ \\
\hline $\begin{array}{l}\text { Family Phalangeridae } \\
\text { Trichosurus vulpecula } 1,2,3 \\
\text { Pseudocheirus peregrinus } 1,2,4\end{array}$ & $\begin{array}{l}\text { Family Phalangeridae } \\
\text { Schoinobates volans } 11\end{array}$ & \multirow{6}{*}{$\begin{array}{l}\text { Family Peramelidae } \\
\text { Isoodon obesulus } 20,21,22 \\
(=\text { Perameles obesula }) \\
\text { Perameles gunii }{ }^{22} \\
\text { Peramales nasuta } 2,22,23 \\
\text { Echymipera rufescens }^{6}\end{array}$} \\
\hline \multirow{3}{*}{$\begin{array}{l}\text { Family Macropodidae } \\
\text { Protemnodon rufogrisea } \\
\text { Setonix brachyurus }^{1,5} \\
\text { Potorous tridactylus }^{1,2} \\
\text { Macropus robustus }^{6} \\
\text { Macropus giganteus }^{7} \\
\left(=\text { Macropus major }^{8}\right)\end{array}$} & $\begin{array}{l}\text { Dasyurus viverrinus }{ }^{12} \\
\text { Sminthopsis crassicaudata }\end{array}$ & \\
\hline & $\begin{array}{l}\text { Family Macropodidae } \\
\text { Macropus eugenii } 13,14,15 \\
\text { Bettongia cuniculus } \\
16\end{array}$ & \\
\hline & Family Phascolarctidae & \\
\hline \multirow{2}{*}{$\begin{array}{l}\text { Family Didelphidae } \\
\text { Didelphis marsupialis } 9,10 \\
\text { (=Didelphis virginiana) }\end{array}$} & $\begin{array}{l}\text { Phascolarctos cinereus } 2,17 \\
\text { Vombatus ursinus } 18\end{array}$ & \\
\hline & $\begin{array}{l}\text { Family Didelphidae } \\
\text { Philander opossum } 19\end{array}$ & \\
\hline
\end{tabular}

References: ${ }^{1}$ Sharman (1961); ${ }^{2}$ Hughes \& McNally (1968); ${ }^{3}$ Hughes (1974); ${ }^{4}$ Hughes, Thomson \& Owen (1965); ${ }^{5}$ Sharman (1959); ${ }^{6}$ Hughes (this investigation); ${ }^{7}$ Chapman (1882); ${ }^{8}$ Owen (1834); ${ }^{9}$ Hartman (1923); ${ }^{10} \mathrm{McCrady}(1938) ;{ }^{1}$ Bancroft $(1973) ;{ }^{12} \mathrm{Hill}$ (1900); ${ }^{13}$ Renfree (1972); ${ }^{14}$ Renfree (1973); ${ }^{15}$ Tyndale-Biscoe (1973); ${ }^{16}$ Flynn (1930); ${ }^{17}$ Caldwell (1884); ${ }^{18} \mathrm{E}$. C. Amoroso (personal communication); ${ }^{19}$ Enders \& Enders (1969); ${ }^{20} \mathrm{Hill}(1895) ;{ }^{21} \mathrm{Hill}(1897) ;{ }^{22}$ Flynn (1923); ${ }^{23} \mathrm{~A} . \mathrm{G}$. Lyne (personal communication). 
concerned. The duration of this second developmental period approximately coincides with the terminal third of pregnancy and occupies the greater part or possibly slightly more than the whole of this period (Table 1).

Observations on the extent of trophoblastic invasiveness in marsupial species representing six families are summarized in Table 2. Three categories are recognized as follows: not invasive, slightly invasive, and highly invasive. It can be seen from Table 2 that, in the Phalangeridae, Macropodidae and Didelphidae, species are represented with both the non-invasive and slightly invasive type of trophoblast. Possibly the simplest explanation for this would be that trophoblastic invasiveness has evolved independently at least once within each of these marsupial families.

The three types of trophoblastic invasiveness will now be considered separately with particular attention devoted to a representative marsupial species for each group as follows: not invasive, Trichosurus vulpecula; slightly invasive, Phascolarctos cinereus; highly invasive, Perameles nasuta.

\section{Marsupials with a non-invasive trophoblast}

Early studies on Macropus major (Owen, 1834) and Didelphis virginiana (Michel, 1850) showed that the fetal membranes were not attached to the uterus during the terminal stages of pregnancy and similar observations have since been made for a wide variety of marsupial species (Table 2). Hartman (1923) found that although Didelphis virginiana embryos were not attached to the uterine wall up to the time of birth, the ectoderm of the trophoblast closely followed the contour of the folded uterine epithelium.

In Plate 1, Fig. 4, trophoblast investing an advanced pregnancy stage of Potorous tridactylus can be seen. The trophoblastic ectoderm consisted of a small region of true chorion, and both bilaminar and vascularized trilaminar portions of the yolk-sac and was not at any point attached to the uterine epithelium. Likewise in Trichosurus vulpecula the trophoblast never invades the uterine epithelium and in advanced pregnancy extensive portions of the ruptured shell membrane can often be found separating the trophoblast from the uterine epithelium (Pl. 1, Fig. 3). Sharman (1961) also has reported a lack of attachment between the epithelia of fetal and maternal tissues in both Potorous tridactylus and Trichosurus vulpecula during the advanced pregnancy stages.

Sharman (1961) made detailed studies of the relationship of the embryonic membranes to the uterine epithelium in five genera of diprotodont marsupials: Trichosurus vulpecula, Pseudocheirus peregrinus, Protemnodon rufogrisea, Setonix brachyurus and Potorous tridactylus. His observations showed that in all species the uterine luminal epithelium remains complete throughout pregnancy. The uterine epithelium is well vascularized in Trichosurus vulpecula and Pseudocheirus peregrinus and in the latter species the embryonic and maternal blood streams are brought into close proximity by the displacement of nuclei from the cell layers separating the blood vessels. In the remaining species (all macropod marsupials) the uteri are relatively avascular and embryonic and maternal blood streams are well separated. It should also be noted that Sharman (1961) did not confirm Caldwell's (1884) observation of an attachment between the fetal trophoblastic epithelium (bilaminar yolk-sac) and the uterine epithelium in Protemnodon rufogrisea (= Halmaturus ruficollis). 
It may therefore be concluded that marsupial species without an invasive trophoblast do not exhibit implantation at any stage of pregnancy.

\section{Marsupials with a slightly invasive trophoblast}

Observations on two full-term koala (Phascolarctos cinereus) embryos have shown that enlarged ectodermal cells in an annular zone of the non-vascular bilaminar yolk-sac, just outside the sinus terminalis, were united with the uterine luminal epithelium. This union is considered to be a form of rudimentary implantation and was mostly achieved by relatively shallow interdigitation between fetal and maternal cell processes (Pl. 2, Fig. 5) although enlarged fetal cells occasionally penetrated the maternal epithelium (Pl. 2, Fig. 6). Although the vesicular allantois of the koala embryo was fused with the chorion, no chorionic villi were present, and no fusion of the chorion with the uterine epithelium was evident (Pl. 2, Figs 7 and 8). No attachment was found in the region of the vascularized trilaminar yolk-sac.

These observations confirm those previously reported for the koala by Caldwell (1884), and Amoroso (1952 and personal communication) has made comparable observations in the wombat, Phascolomis mitchelli (=Vombatus ursinus).

In Bettongia cuniculus (Flynn, 1930), Philander opossum (Enders \& Enders, 1969), Macropus eugenii (Tyndale-Biscoe, 1973 and personal communication) and Schoinobates volans (Bancroft, 1973), which all exhibit rudimentary implantation, the invasive properties of the trophoblastic ectoderm are found in regions of the vascular portion of the yolk-sac near the sinus terminalis and not in the avascular region as described for Phascolarctos cinereus.

In Macropus eugenii the second phase of embryonic development begins with the loss of the shell membrane after 19 to 20 days of the 27 days of gestation

\section{EXPLANATION OF PLATE 2}

Fig. 5. Portion of a transversely sectioned uterus of a full-term pregnant koala, Phascolarctos cinereus. The fetus is shown in Figs 7 and 8 . The micrograph shows enlarged ectodermal cells from an annular zone of the nonvascular, bilaminar yolk-sac (ECT BI YS) just outside the sinus terminalis, united with cells (arrowed) of the uterine Iuminal epithelium (UT EP).

Fig. 6. Portion of a transversely sectioned uterus of a full-term pregnant koala. Phascolarctos cinereus, in a region similar to that shown in Fig. 5. An enlarged ectoderm cell from the bilaminar yolk-sac (ECT BI YS) has penetrated (arrowed) the luminal epithelium of the uterus (UT EP).

Fxg. 7. A fixed full-term koala, Phascolarctos cinereus, fetus (17 $\mathrm{mm} \mathrm{long)} \mathrm{in} \mathrm{relation} \mathrm{to} \mathrm{its}$ partly dissected fetal membranes. Three regions of the fetal membranes were adjacent to the luminal epithelium of the uterus as follows: (a) A fused chorio-allantoic membrane (CH AL). Although the vesicular allantois was fused with the chorion, no chorionic villi were present and the chorio-allantoic membrane was not attached to the uterine epithelium. (b) A vascularized trilaminar yolk-sac (removed by dissection) occupying approximately half the external portion of the fetal membranes and bounded by an equatorial sinus terminalis. (c) A bilaminar nonvascularized portion of the yolk-sac (removed by dissection) including the annular zone of attachment just outside the sinus terminalis. The limiting fetal membranes were oval and had a major and a minor axis of 34.5 and 20 mm respectively.

Fig. 8. A fixed, full-term koala, Phascolarctos cinereus, fetus showing a further stage in the dissection of the fetal membranes of the specimen shown in Fig. 7. The vesicular allantois (ALT) of $12 \mathrm{~mm}$ in diameter had a poorly developed umbilical cord and was fused with the chorion to form a chorio-allantoic membrane (CH AL). This fusion was confirmed by histological sections. The amnion (AM) closely invested the fetus. 




fracing p. 180 


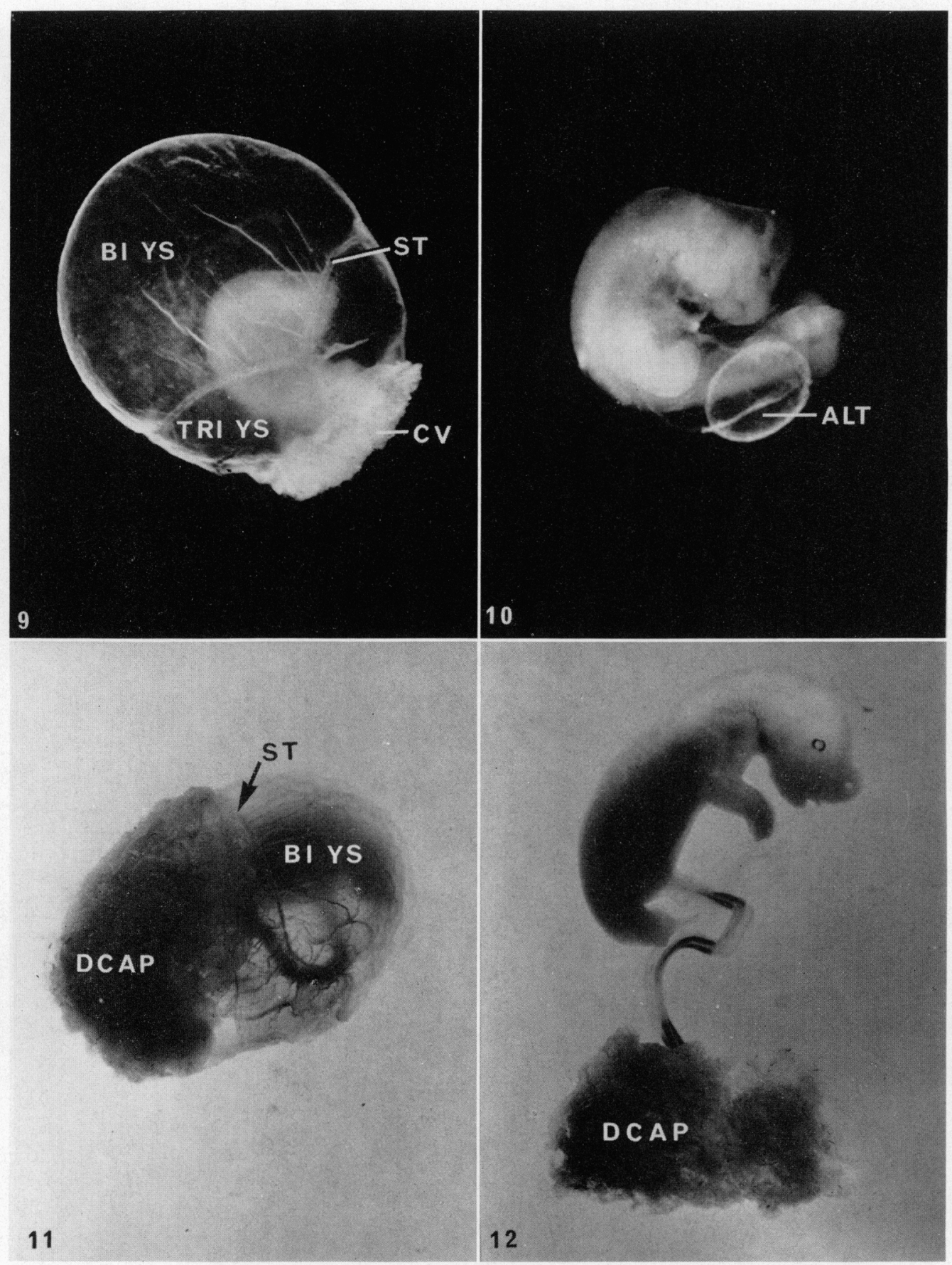


had elapsed (Renfree, 1973). Interdigitation occurs between the microvillous surfaces of the embryonic and uterine epithelia (Tyndale-Biscoe, 1973) but there is no erosion of maternal tissues and junctional complexes are not formed with the uterine cells (C. H. Tyndale-Biscoe, personal communication). However, a more intimate union occurs in Philander opossum (Enders \& Enders, 1969). The fetal ectodermal cells form cups overlying the tops of the endometrial folds and giant cells penetrate between the uterine cells into the endometrial stroma and may form junctional complexes with the uterine cells.

Hill (1900) reported the development of a very intimate union of fetal and maternal tissues in an annular zone of the non-vascular bilaminar yolk-sac just outside the sinus terminalis in Dasyurus viverrinus. In this zone pseudopodialike processes arose from enlarged trophoblastic ectodermal cells and did not simply fit between the cells of the uterine epithelium but penetrated to the subepithelial tissues. This rudimentary implantation resulted in erosion of the maternal epithelium, and fetal cell processes eventually grew around and enclosed some of the capillaries underlying the maternal epithelium. The fetal trophoblastic ectoderm was believed to be finally converted into a syncytium and blood sinuses were said to be formed from the maternal capillaries. Hill (1900) also reported that the ectodermal cells of the vascularized region of the yolk-sac accurately followed the contour of the ridged uterine surface and that the fetal ectodermal cells appeared to be in intimate and actual fusion with the uterine epithelium. Hill found that the chorion of Dasyurus viverrinus was closely applied to the uterine epithelium over a greater or lesser portion of its surface.

In Sminthopsis crassicaudata the mode of implantation closely resembles that of Dasyurus viverrinus with attachment between fetal and maternal tissues occurring in the region of the bilaminar yolk-sac, the trilaminar yolk-sac and the chorion. The pregnancy stages of Sminthopsis crassicaudata concerned were obtained from a single female in an advanced stage of gestation and Dr G. K.

\section{EXPLANATION OF PLATE 3}

Frg. 9. A preserved specimen, showing an early implantation stage of Perameles nasuta. The fetus had an overall length of $6.5 \mathrm{~mm}$, not allowing for the curvature of the body, and was completely invested by fetal membranes in which three regions could be recognized. The non-vascularized bilaminar portion of the yolk-sac (BI YS) was separated from the vascularized trilaminar region of the yolk-sac (TRI YS) by the equatorial sinus terminalis (ST). A small, thickened discoidal area of the chorion of about $6.3 \mathrm{~mm}$ in diameter was firmly united with the uterine endometrium by chorionic villi (GV). The major and minor axes of the limiting fetal membranes were $13.5 \mathrm{~mm}$ and $12.0 \mathrm{~mm}$ respectively.

Frg. 10. A preserved, early implantation stage of Perameles nasuta showing the fetus and a further stage in the dissection of the fetal membranes of the specimen shown in Fig. 9. The allantoic vesicle (ALT) of $2.5 \mathrm{~mm} \times 2.1 \mathrm{~mm}$ was not fused with the chorion.

FIG. 11. A preserved, full-term fetus of Perameles nasuta enclosed within its fetal membranes. The major and minor axes of the limiting fetal membranes were 17 and $11.5 \mathrm{~mm}$ respectively. BI YS, non-vascularized bilaminar yolk-sac. The area of attachment between the chorion and the uterine endometrium has expanded in comparison with the early implantation stage (Fig. 9). A discoidal chorio-allantoic placenta (DCAP) of $11.5 \mathrm{~mm}$ $\times 10 \mathrm{~mm}$ had differentiated. The sinus terminalis (ST) was less well developed than the blood vessels that supplied the discoidal chorio-allantoic placenta.

Frg. 12. A further stage in the dissection of the specimen shown in Fig. 11. The fetus had an overall length of $13.8 \mathrm{~mm}$, not allowing for the curvature of the body. An umbilical cord (with a single loop) connected the fetus with the discoidal chorio-allantoic placenta (DC AP). 
Godfrey (personal communication) considered that the female had completed at least 12 days of the 16 days of gestation. Both uteri contained fetuses with an overall length of $2.5 \mathrm{~mm}$. The head region of the fetuses was incompletely differentiated and exhibited prominent branchial clefts. The allantois was small $(0.5 \mathrm{~mm}$ in diameter), dense and club-shaped and was not fused with the chorion. Ruptured remnants of the shell membrane were found. The most intimate attachment between fetal and maternal tissues occurred at discontinuous areas in an annular zone of bilaminar yolk-sac adjacent to the sinus terminalis. Here fetal ectodermal cells, much larger than those in the remainder of the bilaminar yolk-sac, interdigitated with those of the luminal maternal epithelium, and this was particularly evident at the tops of uterine folds. The areas of attachment were relatively numerous and often exhibited extensive erosion of the maternal epithelium with fetal elements penetrating into the subepithelial connective tissue. Single cells or groups of cells of the uterine epithelium were frequently found completely enclosed by the cytoplasm of the fetal ectodermal cells. A syncytium had not formed in either the fetal or maternal cells in the area of attachment, or at any other point. The endothelial cells of the maternal capillaries were intact and no blood sinuses were found.

A less intimate type of attachment between fetal and maternal elements in Sminthopsis crassicaudata was found in the vascularized region of the trilaminar yolk-sac, particularly near the sinus terminalis. Here interdigitation occurred between the fetal ectodermal cells and the uterine luminal epithelium and small areas of fusion between fetal and maternal epithelial cells were occasionally found. However, the maternal epithelium was not penetrated by the fetal trophoblast cells. A similar relationship between fetal and maternal tissues was also found in the region of the chorion.

\section{Marsupials with a highly invasive trophoblast}

Such species are all members of a single family, the Peramelidae. Unlike those marsupials that exhibit the rudimentary type of implantation, attachment in the peramelids is effected by highly invasive villi of enlarged chorionic cells and is a preliminary to the differentiation of the discoidal chorio-allantoic placenta.

The phenomenon of chorio-allantoic placentation in marsupials was first described for Isoodon obesulus (=Perameles obesula) by Hill $(1895,1897)$ and these findings were later reviewed and extended by Flynn (1923) to include Perameles gunii and Perameles nasuta. The significance of these early studies together with ome re-interpretation have been discussed by Pearson (1949), Hill (1949) and Amoroso (1952). Both the mode of embryonic attachment to the uterine epithelium (implantation) and subsequent differentiation of the discoidal chorioallantoic placenta are unique to the Peramelidae among marsupial families and, according to Hill (1949), probably evolved independently within this group.

Flynn (1923) described the first fixation of the chorion to the vascularized uterine syncytium in a $6.1-\mathrm{mm}$ embryo of Isoodon obesulus and in the present context this is considered to represent an early stage in implantation. The chorion of Isoodon obesulus was attached to the uterine syncytium over a small 
area but the allantoic vesicle of $5 \mathrm{~mm} \times 3.1 \mathrm{~mm}$ had not yet fused to form the conjoint chorio-allantoic layers. An equivalent stage of implantation in Perameles nasuta is shown in Pl. 3, Figs 9 and 10. According to Dr A. G. Lyne (personal communication) this stage is attained at about the 7 th to 9 th days of the $12 \pm 1$ days of gestation (Hughes, 1962).

In describing the newly implanted Isoodon obesulus embryo, Flynn (1923) found that over a very small area the trophoblast (true chorion) was attached to the thickened maternal syncytium (trophospongia). The chorionic ectoderm in the region of attachment was single layered, and at certain points the ectodermal cells had proliferated to form a syncytial structure with irregular contours, due to the presence of pseudopodial processes. At various points the nuclei of this fetal plasmodial structure had invaded highly vascularized, thickened syncytial nests of the uterine epithelium. The openings of the uterine glands were occluded by this invasion of fetal tissues. The cells of the fetal plasmodiblast were phagocytic and had engulfed some maternal syncytial nuclei and gland nuclei. In subsequent developmental stages the area of chorionic invasion progressively enlarged. The splanchnic mesoderm of the allantois became intimately fused with the somatic mesoderm of the chorion, and at the terminal stage of pregnancy the chorio-allantois had differentiated into a discoidal placenta virtually identical with that shown in Pl. 3, Figs 11 and 12 for Perameles nasuta. However, in the Peramelidae, unlike marsupials that exhibit rudimentary implantation, no sign of fusion or connection has been found to develop between the trophoblastic epithelium of the fetal yolk-sac and the uterine epithelium (Pl. 3, Fig. 11).

In an early fetal stage (greatest length $5.0 \mathrm{~mm}$ ) of Echymipera rufescens the chorion and adjacent luminal epithelium of the uterus exhibited localized thickening, typical of the preimplantation stage of other peramelid species. Only remnants of the shell membrane remained, and a syncytium had not formed in either the fetal or maternal epithelium.

Flynn (1923) considered that the method of placentation in Perameles resembled that of eutherian mammals and that differences between the two were only of degree. A somewhat similar view was proposed by Amoroso (1952) who suggested that the attachment of the blastocyst of Perameles by enlarged chorionic ectodermal cells to a thickened discoidal area of vascularized uterine syncytium was analogous to the symplasma of eutherian mammals.

\section{CONGLUSIONS}

It is now well established that the majority of kangaroo-like marsupials (Macropodidae) return to oestrus within a few days after giving birth. Post-partum fertilization at this time leads to the formation of a unilaminar blastocyst. Mitotic activity ceases within the blastocyst wall, however, until the terminal stages of pouch life when lactation becomes intermittent, or, less frequently, the blastocyst remains dormant after the pouch-young is weaned and development of the blastocyst is completed at the beginning of the next breeding season (Sharman \& Berger, 1969). 
Tyndale-Biscoe (1963) reported that in kangaroo-like marsupials the embryo was arrested at the unilaminar blastocyst stage as in eutherian mammals that exhibited delayed implantation but, unlike them, implantation of the blastocyst did not take place immediately after the resumption of development. Indeed, implantation was not associated with the phenomenon at all and accordingly Tyndale-Biscoe suggested that it should more correctly be termed 'embryonic diapause'. Enders (1967) commented on embryonic diapause in marsupials as follows: "Since the delay occurs prior to the swelling stage of the blastocyst, it is more accurately a delayed development or quiescent stage of the blastocyst than a delay of implantation". It is also worth noting that the present review has shown that species of the Macropodidae resemble other marsupials in possessing an intact shell membrane that serves as a barrier to implantation during the period of blastocyst expansion.

In considering the possible evolutionary steps that might link a marsupialtype and the eutherian mode of implantation, the timing of the trophoblast attachment to the uterine epithelium is of obvious importance. A wide variety of marsupial species do not exhibit the phenomenon of implantation during the course of their embryonic development. In those marsupials in which implantation does occur it is, with the exception of the Peramelidae, of a rudimentary type.

Marsupial implantation is universally widely separated in time from the appearance of the postovulatory proliferative phase in the uterus, and implantation always occurs during the terminal stages of gestation, after the onset of fetal differentiation, during the last third of pregnancy. Thus, unlike eutherian species, the phenomenon of marsupial implantation is not closely integrated in time with the early postovulatory stimulation (or its equivalent) of the uterine endometrium by gonadal hormones.

A closer resemblance to the eutherian condition could be achieved by evolutionary adaptations relating to at least three important aspects: a shifting of the invasive phase of the marsupial trophoblast progressively towards the earlier stages of pregnancy; this would necessitate the progressively earlier rupture of the shell membrane and, as in eutherians, its eventual disappearance; presumably these changes would also require an integration of the implantation phenomenon into the endocrine patterns of progressively earlier stages of gestation.

\section{AGKNOWLEDGMENTS}

I wish to thank Dr Gillian K. Godfrey of the Chicago Zoological Park, Illinois, for the two pregnancy stages of Sminthopsis crassicaudata. Thanks are also due to Mr J. McNally, National Museum of Victoria, for the specimens of Phascolarctos cinereus and to Mr K. Keith, G.S.I.R.O. Division of Wildlife Research, for the pregnancy stage of Echymipera rufescens. I am very grateful for the personal communications of Professor E. C. Amoroso, A.R.G. Institute of Animal Physiology, Babraham, Cambridge, England; to Dr A. G. Lyne, C.S.I.R.O. Division of Animal Physiology, Sydney, Australia; and to Dr C. H. TyndaleBiscoe, Department of Zoology, Australian National University, Canberra, 
Australia. I would also like to express my appreciation to Mr Bob McBlain, School of Zoology, University of New South Wales, who assisted in the preparation of the photographic plates from colour slides.

\section{REFERENCES}

Amoroso, E. G. (1952) Placentation. In Marshall's Physiology of Reproduction, 3rd edn, Vol. 2, p. 127. Ed. A. S. Parkes. Longmans Green, London.

Bancroft, B. J. (1973) Embryology of Schoinobates volans (Kerr) (Marsupialia : Petauridae). Aust. F. Zool. $21,33$.

Boyd, A. N. (1924) Histological changes in the Fallopian tubes of the opossum during the phases of the estrous cycle. M.A. thesis, University of Texas.

Вroом, R. (1895) Note on the period of gestation in Echidna. Proc. Linn. Soc. N.S.W. 10, 576.

CALDWELL, W. H. (1884) On the arrangement of the embryonic membranes in marsupial animals. Q. 7 l microsc. Sci. 24, 655 .

Caldwell, W. H. (1887) The embryology of Monotremata and Marsupialia. Part 1. Phil. Trans. R. Soc., B, 178, 463.

Chapman, H. G. (1882) On a foetal kangaroo and its membranes. Ann. Mag. nat. Hist. 9, 338.

EnDERs, A. G. (1967) The uterus in delayed implantation. In Cellular Biology of the Uterus, p. 151. Ed. R. M. Wynn. Appleton-Gentury-Crofts, New York.

Enders, A. C. \& Enders, R. K. (1969) The placenta of the four-eyed opossum (Philander opossum). Anat. Rec. 165, 431 .

EwER, R. F. (1968) A preliminary survey of the behaviour in captivity of the dasyurid marsupial, Sminthopsis crassicaudata (Gould). Z. Tierpsychol. 25, 319.

FLynn, T. T. (1923) The yolk-sac and allantoic placenta in Perameles. Q. Fl microsc. Sci. 67, 123.

FLYNN, T. T. (1930) The uterine cycle of pregnancy and pseudopregnancy as it is in the diprotodont marsupial Bettongia cuniculus. Proc. Linn. Soc. N.S.W. 55, 506.

Hartman, G. G. (1916) Studies in the development of the opossum Didelphis virginiana L. I. History of the early cleavage. II. Formation of the blastocyst. F. Morph. 27, 1.

Hartman, G. G. (1919) Studies in the development of the opossum Didelphis virginiana L. III. Description of new material on maturation, cleavage and endoderm formation. IV. The bilaminar blastocyst. F. Morph. 32, 1.

Hartman, G. G. (1923) Breeding habits, development and birth of the opossum. Rep. Smithson. Instn, $1921,347$.

Hartman, G. G. (1928) The breeding season of the opossum (Didelphis virginiana) and the rate of intrauterine and postnatal development. F. Morph. 46, 143.

Hartman, G. G. (1939) Ovulation, fertilization and the transport and viability of eggs and spermatozoa. In Sex and Internal Secretions, Chap. 10. Williams \& Wilkins, Baltimore.

Hibl, J. P. (1895) Preliminary note on the occurrence of a placental connection in Perameles obesula, and on the foetal membranes of certain macropods. Proc. Linn. Soc. N.S.W. 10, 578.

Hill, J. P. (1897) The placentation of Perameles. Q. Jl microsc. Sci. 40, 385.

HrLi, J. P. (1900) On the foetal membranes, placentation and parturition of the native cat (Dasyurus viverrinus). Anat. Anz. 18, 364.

Hill, J. P. (1910) The early development of the Marsupialia, with special reference to the native cat (Dasyurus viverrinus). Q. Fl microsc. Sci. 56, 1.

HiLl, J. P. (1918) Some observations on the early development of Didelphis aurita. Q. Fl microsc. Sci. 63,91 .

Hriz, J. P. (1949) The allantoic placenta of Perameles. Proc. Linn. Soc. Lond. 161, 3.

Hughes, R. L. (1962) Role of the corpus luteum in marsupial reproduction. Nature, Lond. 194, 890,

Hughes, R. L. (1974) The tertiary egg membranes of the marsupial Trichosurus vulpecula. Ph.D. thesis, School of Zoology, University of New South Wales.

Hughes, R. L. \& McNally, J. (1968) Marsupial foetal membranes with particular reference to placentation. 7. Anat. 103, 211.

Hughes, R. L., Thomson, J. A. \& Owen, W. H. (1965) Reproduction in natural populations of the Australian ringtail possum, Pseudocheirus peregrinus (Marsupialia: Phalangeridae), in Victoria. Aust. 7. Zool. 13, 383.

KRRR, T. (1935) Notes on the development of the germ layers in diprotodont marsupials. Q. Fl microsc. Sci. 77, 305.

McGrady, E. (1938) The embryology of the opossum. Am. anat. Mem. No. 16.

Michet, M. (1850) Researches on the generation and development of the opossum. Proc. Am. Ass. Advmt Sci. 3, 60 . 
OWEN, R. (1834) On the generation of the marsupial animals with a description of the impregnated uterus of the kangaroo. Phil. Trans. R. Soc. 1834, 333.

Pearson, J. (1949) Placentation of the Marsupialia. Proc. Linn. Soc. Lond. 161, 1.

RENFREE, M. B. (1972) Embryo-maternal relationships in the tammar wallaby Macropus eugenii (Desmarest). Ph.D. thesis, Department of Zoology, Australian National University.

Renfree, M. B. (1973) The composition of fetal fluids of the marsupial Macropus eugenii. Devl Biol. 33, 62 .

Sharman, G. B. (1959) Marsupial reproduction. Monogr. Biol. 8, 332.

Sharman, G. B. (1961) The embryonic membranes and placentation in five genera of diprotodont marsupials. Proc. zool. Soc. Lond. 137, 197.

Sharman, G. B. \& Berger, P. J. (1969) Embryonic diapause in marsupials. Adv. Reprod. Physiol. 4, 211.

Tyndale-Biscoe, G. H. (1963) The role of the corpus luteum in delayed implantation in marsupials. In Delayed Implantation, p. 15. Ed. A. C. Enders. University of Chicago Press.

Tyndale-Biscoe, G. H. (1973) Life of Marsupials. Edward Arnold, London.

Wilson, J. T. \& Hill, J. P. (1908) Observations on the development of Ornithorhynchus. Phil. Trans. R. Soc. B, 199, 31 . 